\title{
Modelling potential current distribution and future dispersal of an invasive species Calliandra calothyrsus in Bali Island, Indonesia
}

\author{
ANGGA YUDAPUTRA ${ }^{*}$ \\ Center of Plant Conservation and Botanic Gardens, Indonesian Institute of Sciences. Jl. Ir. H. Djuanda No.13, Paledang, Bogor 16211, West Java, \\ Indonesia. Tel./fax.: +62-251-8311362-8336871, •email: angg020@lipi.go.id
}

Manuscript received: 1 November 2019. Revision accepted: 21 January 2020.

\begin{abstract}
Yudaputra A. 2020. Modelling potential current distribution and future dispersal of an invasive species Calliandra calothyrsus in Bali Island, Indonesia. Biodiversitas 21: 674-682. Calliandra calothyrsus Meisn. is relatively well-adapted in abandoned areas, degraded lands, and poor nutrient soils. It tends to reproduce rapidly and be invasive in certain landscapes as it often dominates the vegetation. This study aimed to understand the potential current distribution and the population dispersal of $C$. calothyrsus across Bali Island using Random Forest (RF) and Maximum Entropy (MaxEnt) models. Thirteen environmental variables, including several climatic variables, topography, soil characteristics were used as predictors. The occurrence records of $C$. calothyrsus were obtained from direct field survey in which square plots $10 \times 10 \mathrm{~m}$ were used to collect the population structure data. The Rangeshifter software was used to understand the population dynamic and dispersal pattern. The results showed that the two models (RF and MaxEnt) have the AUC $>0.9$ which means those models are excellent in predicting the potential current distribution of $C$. calothyrsus. Furthermore, the RF model has the TSS and Kappa value of $>0.90$ which means it has almost perfect agreement between the prediction and the real observation. On the other hand, the TSS and Kappa value of MaxEnt were $>0.70$ indicating it has a substantial agreement. The population structure in the field showed that the number of juvenile individuals dominated all plots compared to seedlings and mature individuals. The simulation analysis showed that the population tends to have bigger population in the next 50 years by dispersing throughout neighbor cells or areas in which the origin occurrence points were recorded.
\end{abstract}

Keywords: Calliandra calothyrsus, invasive plant, population structure, population dispersal, species distribution model

\section{INTRODUCTION}

Calliandra calothyrsus Meisn. is a small tree or large shrub belong to Fabaceae family (Macqueen 1992). It normally reaches $6 \mathrm{~m}$ high, but can be up to $12 \mathrm{~m}$ under favorable conditions. The stem is relatively small with maximum diameter at the base about $30 \mathrm{~cm}$, and the bark is blackish-brown. The flower of the plant has many long red stamens with the flowering phase starts from 3-6 months after planting. The fruits have many pods that contain 3-12 seeds and the seeds will mature about 3 months after pollination. The root relatively grows deep and has longlived sprouts up to 20 years (Ad Hoc Panel 1983). C. calothyrsus has a relatively rapid growth at early stage. It often outcompetes other plants at later stage and invades abandoned lands such as roadsides or shifting cultivation fields. It is well adapted at wide range of altitudes, from sea level to $1,860 \mathrm{~m}$ in area with annual precipitation ranges from 700 to 3,000 mm (Lowry and Macklin 1989). It grows well on wide range of soil types from deep volcanic loams to sandy clay (Galang 1988). It occupies area with the range of mean monthly maximum temperatures between 24 and $28^{\circ} \mathrm{C}$ and means minimum temperatures of $18-24^{\circ} \mathrm{C}$ (Wiersum and Rika 1992).

Calliandra calothyrsus is native to humid and subhumid regions of Central America to Mexico. In 1936, this plant was introduced from Guatemala to Java. Recently, the plant is easily found throughout the Indonesian archipelago and in other parts of Southeast Asia. It was widely utilized as source of green manure and shade for coffee plantation at that time (Verhoef 1939). During the 1970s, it was massively planted in many areas in Java and other regions of Indonesia sponsored by the Indonesian State Forest Corporation (Perum Perhutani). The program was intended to achieve the term of a true self-perpetuating greening movement (Palmer et al. 1994). Many benefits of this plant have been generated since the first year of introduction in Java. Local people have been used the stem as firewood, the young foliage to feed livestock, and the nectar for producing bees honey (Hauser et al. 2006). It is considered a pioneer plant because it can grow in poor soil conditions with limited nutrient availability. It adapts easily to various soil types and is tolerant to wide range of environmental factors such as altitude, rainfall, and light intensity. Furthermore, it is potentially used to fix nitrogen from atmosphere and improve soil fertility and stability (Ad Hoc Panel 1983). It tends to be more adaptive in extreme conditions (e.g. lack of nutrients, poor soil quality and abandoned land) as well as has highly reproduction ability and wide seed dispersal. It was considered an invasive plant in several regions. It was recently invading Karibia, Hawai, Uganda, Dominican Republic, and Indonesia (Kairo et al. 2003; Orwa et al. 2009; Setyawati et al. 2015). It was widely introduced to the tropic and sub-tropic region and recorded as an invasive plant based on Invasive Species Compendium (CABI 2017). According to these reasons, this plant is often considered as invasive species that can negatively impact biodiversity by displacing native species. 

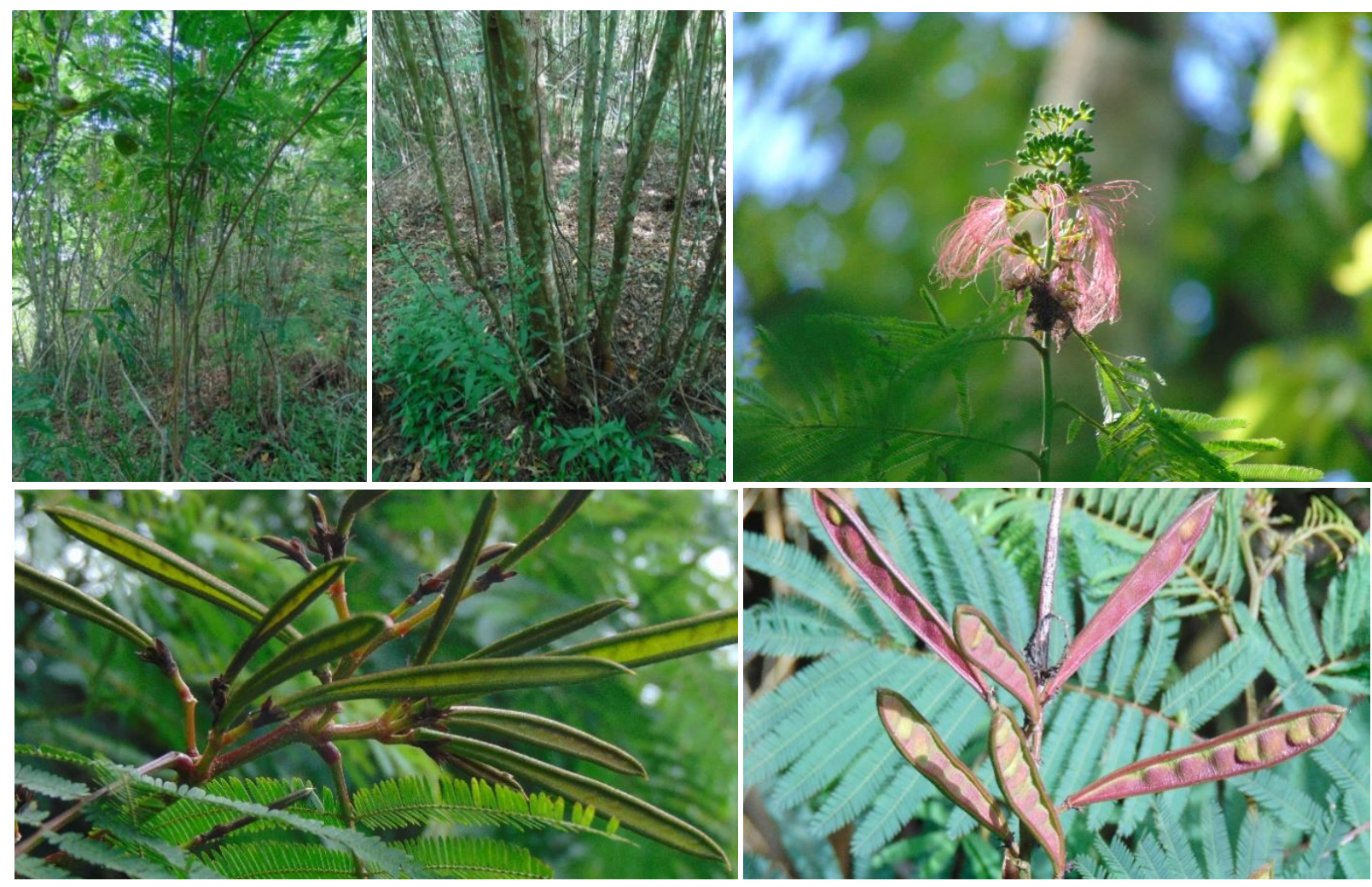

Figure 1. The morphology of Calliandra calothyrsus

Invasive species are defined as non-native or alien species that occupy and dominates particular landscape or ecosystem. Invasive plants are more likely to be successful to establish and spread in a landscape because many invasive plants are able to produce seeds in high quantities which are easily dispersed by wind or birds. They can adapt to disturbed soil or abandoned land with poor soil nutrients. Some invasive plants have aggressive root systems that rapidly grow over large areas, some of them produce chemical substances that inhibit other organisms to live in its surrounding. The invasion of alien species in an environment causes many problems, such as threatening native species moreover the threatened and endangered species, increasing the risk of soil erosion, and contributing to the poor quality of agricultural lands (USDA 2019). For landscape management purposes, understanding the potential invasion of $C$. calothyrsus will be necessary as a consideration regarding proper management control. With fairly rapid population growth, it needs to be monitored for its development in the future. In terms of understanding the distribution and dispersal of invasive alien species, the use of species distribution modelling might be useful for providing information regarding the mitigation and management strategies. Predictive models of species geographic distribution have been used in ecology and conservation (Graham et al. 2004). There are many application of species distribution modelling in ecology, such as modelling the impact of climate change to species distribution (Thomas et al. 2004), modelling the spread pattern of invasive species (Thuiller et al. 2005), and the spatial pattern of species diversity (Graham et al. 2006). Recently, many species distribution models have been developed to understand the pattern of biodiversity distribution.

Random forest (RF) is a machine learning that works based on regression and classification tree (Breiman 2001; Liaw and Wiener 2002). RF is widely used in ecology because it performs better as a classifier (Cutler et al. 2007). Random Forest is a robust predictive model that often used when the number of data points is smaller compared to environmental predictors (Strobl et al. 2007). RF outperforms than other species distribution models (e.g. GLM, GAM, MARS, ANN) (Yudaputra et al. 2019). Furthermore, RF outperforms other predictive models in predicting the distribution of Eusideroxylon zwageri in Kalimantan (Yudaputra et al. 2020). Maximum Entropy (MaxEnt) is a modelling technique that can achieve high predictive accuracy (Phillips and Dudik 2008). There are several advantages using MaxEnt, such as it works both continuous and categorical data, it possibly runs with presence only data, and overfitting can be avoided (Phillips et al, 2006). In recent study, MaxEnt shows the highest Area Under the Curve (AUC) value compared to other species distribution models (e.g. RF, SVM, GLM, BIOCLIM, DOMAIN) in predicting of Guettarda speciosa (Yudaputra et al. 2019).

Area Under the Curve values (AUC) of receiver operator characteristic (ROC) curves, True Skill Statistics 
(TSS), and Kappa statistic are used to measure the accuracy of predictive models. The AUC is often used as a standard to measure the accuracy of species distribution model (Fielding and Bell 1997; Lobo et al. 2008). When the AUC value $>0.5$, it indicates the model works better than random chance (Krzanowski and Hand 2009). The AUC value represents how better model performance in which it can be divided into several categories, i.e. 0.9-1 (excellent), 0.8-0.9 (good), 0.7-0.8 (fair), 0.6-0.7 (poor), and 0.5-0.6 (fail) (Krzanowski and Hand 2009). TSS is often used to evaluate the performance of model prediction and referred to as Pierce skill score (Stephenson 2000). The TSS has the range from- 1 to +1 in which the value of +1 indicates perfect agreement and value of zero or less indicates the performance no better than random chance. The value of TSS is categorized as follows, < 0.4 were poor, 0.4-0.8 useful, and >0.8 good to excellent (Allouche et al. 2006). Kappa represents the agreement between two binary variables. Kappa is a measurement that also used in species distribution modelling. The score of Kappa can be defined as follows, $0=$ agreement equivalent to chance, $0.1-0.20=$ slight agreement, $0.21-0.40=$ fair agreement, $0.41-0.60=$ moderate agreement, $0.61-0.80=$ substantial agreement, 0.81-0.99 = near perfect agreement, $1=$ perfect agreement (Stephanie 2014).

Plant population dynamic refers to how the populations change in their number through space and time by quantifying their births, deaths, immigration, and emigrations. The populations tend to exponentially increase when they occupy in suitable conditions with freely available resources. There are several factors that determine the dynamic of population including demography, weather, soil condition, competitors, herbivore, pathogen, and various hazards (fire) (Watkinson 1997). In case to understand the population growth and dynamic, the use of matrices is strongly recommended. The matrices in ecology that have been widely well known to understand the population growth is Leslie matrix. It was used to model the change of organisms in population over period of time. The Leslie matrix works by dividing population into several groups based on the age classes (Caswell 2001). By combining the spatial analysis and population demography, we could understand how the population disperses in landscape. In study of invasive species, incorporating the correlative model and mechanistic model would produce a useful predictive model (Yudaputra 2019).

\section{MATERIALS AND METHODS}

\section{Modelling potential current distribution}

The current climatic variables were obtained from the global climate data of the new version 2.0. Eight climatic variables were chosen in this study: $\mathrm{BIO} 1=$ Annual Mean Temperature, $\mathrm{BIO} 4=$ Temperature Seasonality (standard deviation *100), BIO5 = Max Temperature of Warmest Month, BIO6 = Min Temperature of Coldest Month, $\mathrm{BIO} 12=$ Annual Precipitation, BIO13 $=$ Precipitation of Wettest Month, BIO14 = Precipitation of Driest Month,
BIO15 = Precipitation Seasonality (Coefficient of Variation). Those climatic data were available on raster format (tiff) for all regions across the globe. The climatic data are extracted from the global climatic data (worldclim.org). The resolution $900 \mathrm{~m}$ (30 arc-second resolution) was chosen for all climatic variables. Physical environment variables were also used as a predictor in this model. Those were elevation, soil $\mathrm{pH}$, soil type, land cover, and evapotranspiration. The topographic data are obtained from the global data (earthexplorer.usgs.gov) and the soil data are extracted from soil grid global data (soilgrids.org). Those variables were chosen because those are suspected as physical environments that determining the distribution pattern of this species. Both climatic and environmental variables should have the same resolution that required to run the species distribution modelling. The variables which have finer resolution were downgraded as the other variables. All spatial data in raster format (tiff) were clipped to align with the study area (Bali). Those clippedclimatic variables and physical environment variables were then used for modelling process in $\mathrm{R}$ open sources.

Two algorithms of species distribution model were used to model potential current and future distribution of $C$. calothyrsus. Those algorithms were Random Forest (RF) and Maximum Entropy (MaxEnt). Several R packages were used in this modelling such as "dismo" was used to load climate variables, "randomforest" was used to run Random Forest model, "rJava" was used to run the MaxEnt model, "mapview" was used to see the point of occurrences, library "sdm" was used to run several algorithms of species distribution models. All algorithms were run using "bootstrap" with two replications.

\section{Field assessment of population structure}

The population of Calliandra calothyrsus at secondary forest in Pinggan village, Bangli District was used to understand the population dynamic pattern. The population of $C$. calothyrsus was grouped into several classes based on its growth stage. Seedling individuals $(0-2 \mathrm{~m})$, juvenile individuals (2-12 m), mature (individuals that entering the flowering or fruiting phase). Ten plots with size $10 \times 10 \mathrm{~m}$ were established to record the individuals and group them into several classes of growth stage. RANGESHIFTER Ver.1.0 software was used to understand the population dynamics of the species for 40 years.

\section{Modelling population dispersal}

Land use map of Indonesia was used to provide the landscape feature in this model. The map consists of 17 types of land uses and covers all regions of Indonesia. The polygon of the land use map was clipped with the base map of Bali to extract only land-use of Bali. Then, the original land use data projection (i.e. WGS 84) was converted into UTM (Universal Transverse Mercator) coordinate projection. The conversion of coordinate system is needed because the RANGESHIFTER 1.0 requires inputs with UTM projections. Then, the land use data as a polygon with UTM projection was converted into raster format. We used $500 \mathrm{~m}$ resolution in spatial data preparation as inputs. The last steps of spatial data preparation were converting 
format of data from into asci as required in RANGESHIFTER Software.

Point of occurrence data in XLXS or CSV (Comma Delimited) format was loaded into GIS with the coordinate projection was adjusted to UTM. The data was then converted into shapefile (shp) of point occurrence. The shapefile was converted into raster file format with a resolution of $500 \mathrm{~m}$. The last step, raster data was changed into asci format as required in RANNGESHIFTER ver.1.0 software. Land use and point of occurrence should have the same coordinate projection and resolution as inputs of software.

In RANGESHIFTER, the population dynamic data should be fitted with several population parameters. The Leslie matrix population would be helpful to understand the population class. The probabilities of seedlings grow to juvenile (G1 stage), the probabilities juvenile grow to mature individual (G2 stage), the fecundity of mature individual, the age required by mature individuals to produce their offspring, and density dependence. We set the probability of growing phase from seedling to juvenile as 0.6 and the probability of growing from juvenile to mature individual as 0.3 in which both values were derived from calculations. The minimum age of mature individuals to reproduce offspring was approximately 5 years. The survival probability was set to 0.8 , and the fecundity of mature individual was 90 . The density independence was set to 0.1 and mortality probability was 0.2 . If the arrival cells were unsuitable, the models will randomly choose a suitable neighbor cell/grid. Mean distance of $500 \mathrm{~m}$ was used in this dispersal model. The simulation was run for 2 replications. Two hundred individuals per cell were inputted in this model and the proportion of individuals per stage 1 : stage $2=0.6: 0.4$. The simulation was run for 50 years to understand the dynamics of $C$. calothyrsus population across the Bali landscape. The predictive dynamic population maps were created every 10 years throughout 50 years of simulation.

\section{RESULTS AND DISCUSSION}

\section{Results}

Two algorithms of species distribution models were used to predict the potential current distribution of Calliandra calothyrsus. In this study, three parameters of model evaluation were used to evaluate model performance. Those were AUC value, True Skill Statistics (TSS), and Kappa statistic. The AUC value of RF (0.98) was better than that of MaxEnt (0.92) (Table 1). The two models have the AUC value $>0.90$, indicating excellent model performance in predicting the potential current distribution. The TSS value of RF was much higher than that of MaxEnt with 0.90 and 0.72 respectively. The TSS value of $\mathrm{RF}>0.90$ indicating that the performance of model was excellent. On the other hands, the TSS value of MaxEnt $>0.70$ indicating the model performance was good. The last evaluation parameters used in this model were Kappa. The Kappa value of RF was 0.95 which means it has almost perfect agreement between prediction and real observation. Meanwhile, the Kappa value of MaxEnt was 0.79 indicating the model has substantial agreement. RF predicted most accurately three predictors that determine distribution patterns, which were elevation, evapotranspiration, and precipitation (Figure 3). Meanwhile, MaxEnt produced three most important predictors including elevation, temperature, and precipitation (Figure 4). The two models produced almost similar predictive maps of potential current distribution of C. calothyrsus (Figures 5 and 6).

The results of our field survey showed that mature individuals were relatively small in number compared to seedlings and juvenile individuals in which only 3-5 mature individuals were found at each plot. The juvenile individuals were the most dominant in every plot. In population structure analysis, the total of mature individuals was 44, juvenile individuals 354 , and seedlings 109 (Figure 7). Our simulation analysis indicated that population tends to increase rapidly over 50 years of simulation by dispersing in neighboring cells or locations. The population continuously growing for every ten years of simulation.

\section{Discussion}

Species Distribution Models (SDMs) were often used to understand the potential distribution area of a species by incorporating physical environment variables and presence only records or presence-absence records. In this study, thirteen environmental variables were used to run this model because those variables were presumably important in terms of determining the distribution pattern. The selection of environmental variables should consider the presence requirement of the species. The selection of environmental variables was a critical way of determining the accuracy of predictive model. In model calibration, dataset was divided into training and testing data in which training data was used for developing the model, whereas the testing data was used for evaluating the model performance. The testing data for evaluation was ideally obtained from resampling which was considered as independent data. However, splitting data was often considered as the best solution since the time and effort to resample the data were limited. In our analysis, we used the proportion of training data: testing data $=75: 25$. Based on the results of this study, according to three parameters of evaluation (i.e. AUC, TSS, Kappa), the predictive models produced by RF and MaxEnt were categorized as excellent predictive models. Those models were highly recommended to be used in prediction of potential distribution.

Table 1. The evaluation of model performance using the AUC, TSS, and Kappa

\begin{tabular}{llll}
\hline Methods & AUC & TSS & Kappa \\
\hline Random Forest (RF) & 0.98 & 0.90 & 0.95 \\
Maximum Entrophy (MaxEnt) & 0.92 & 0.72 & 0.79 \\
\hline
\end{tabular}



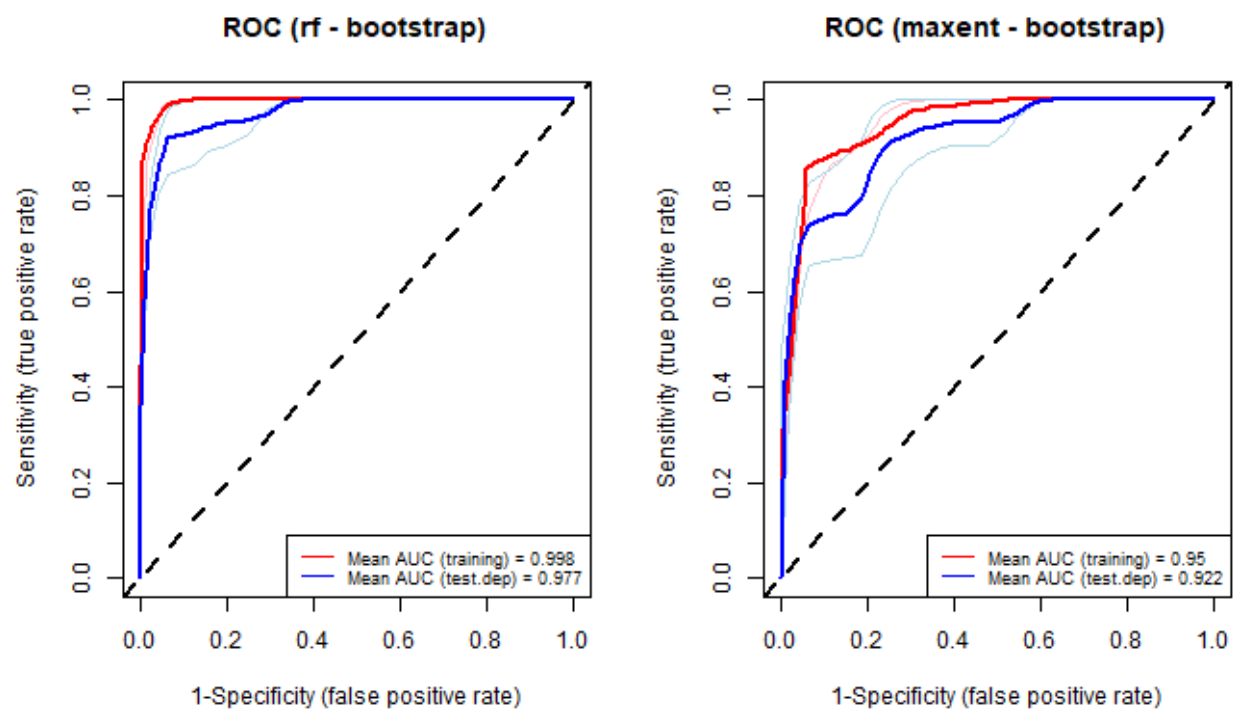

Figure 2. The ROC and AUC value: A. Random Forest (RF); B. Maximum Entropy (MaxEnt)

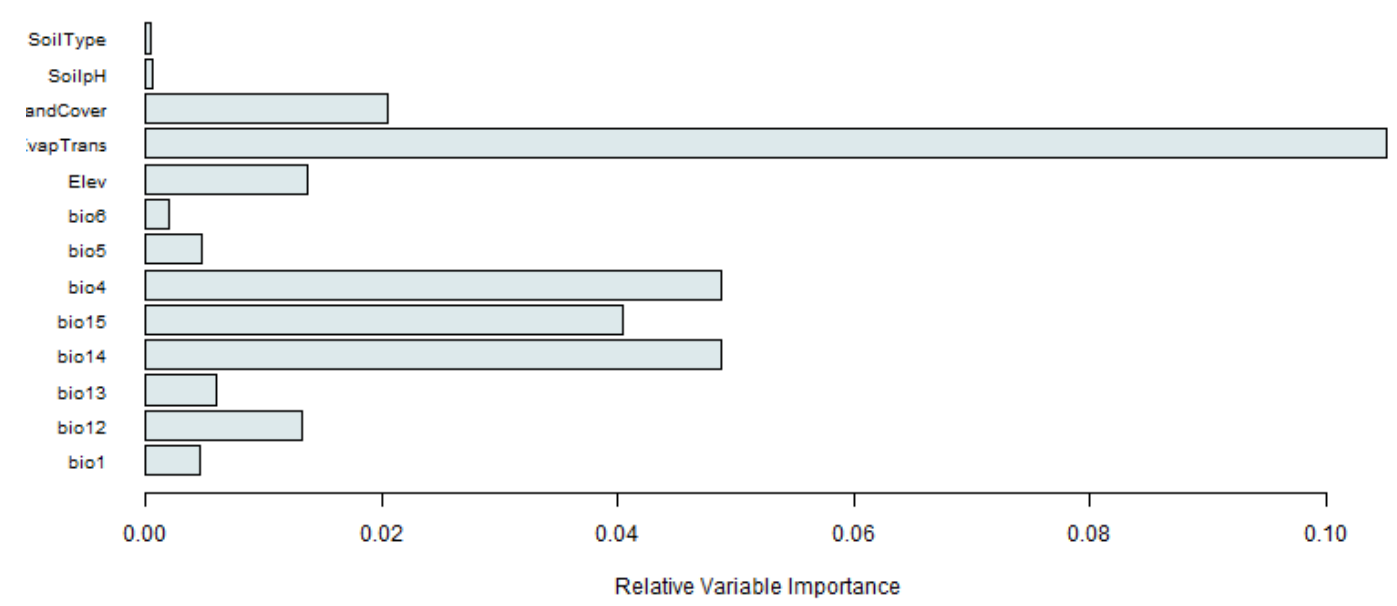

Figure 3. The relative importance of environment variables using Random Forest (RF)

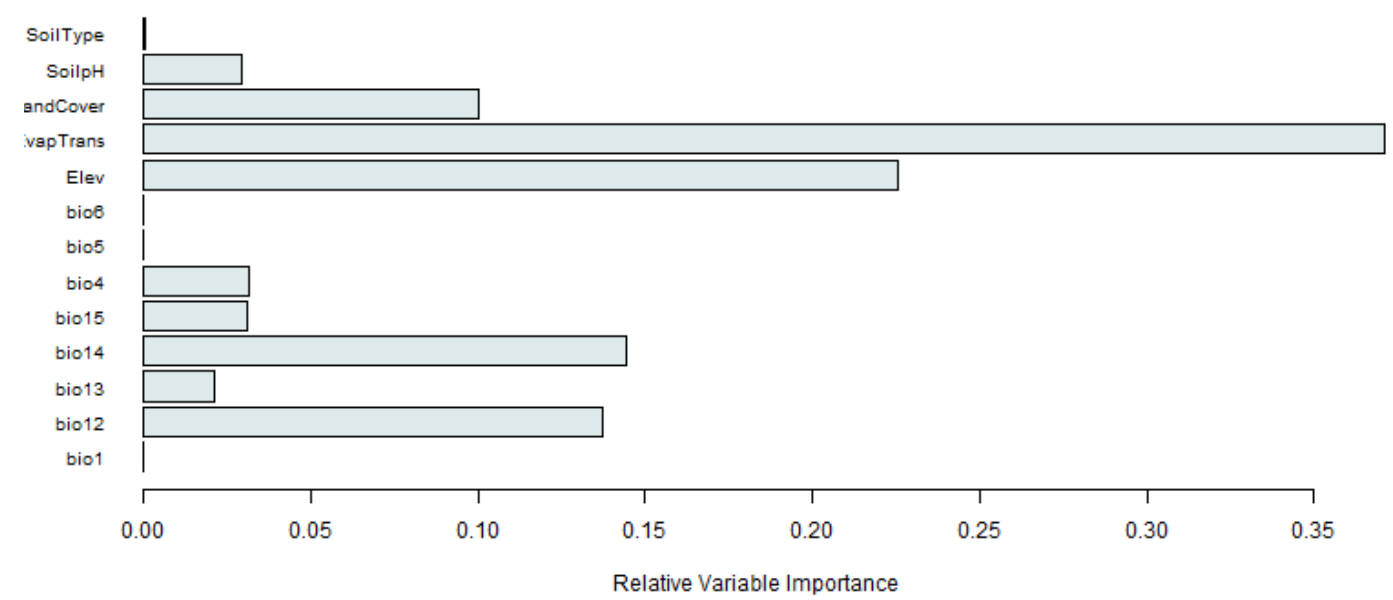

Figure 4. The relative importance of environmental variables using Maximum Entropy (MaxEnt) 


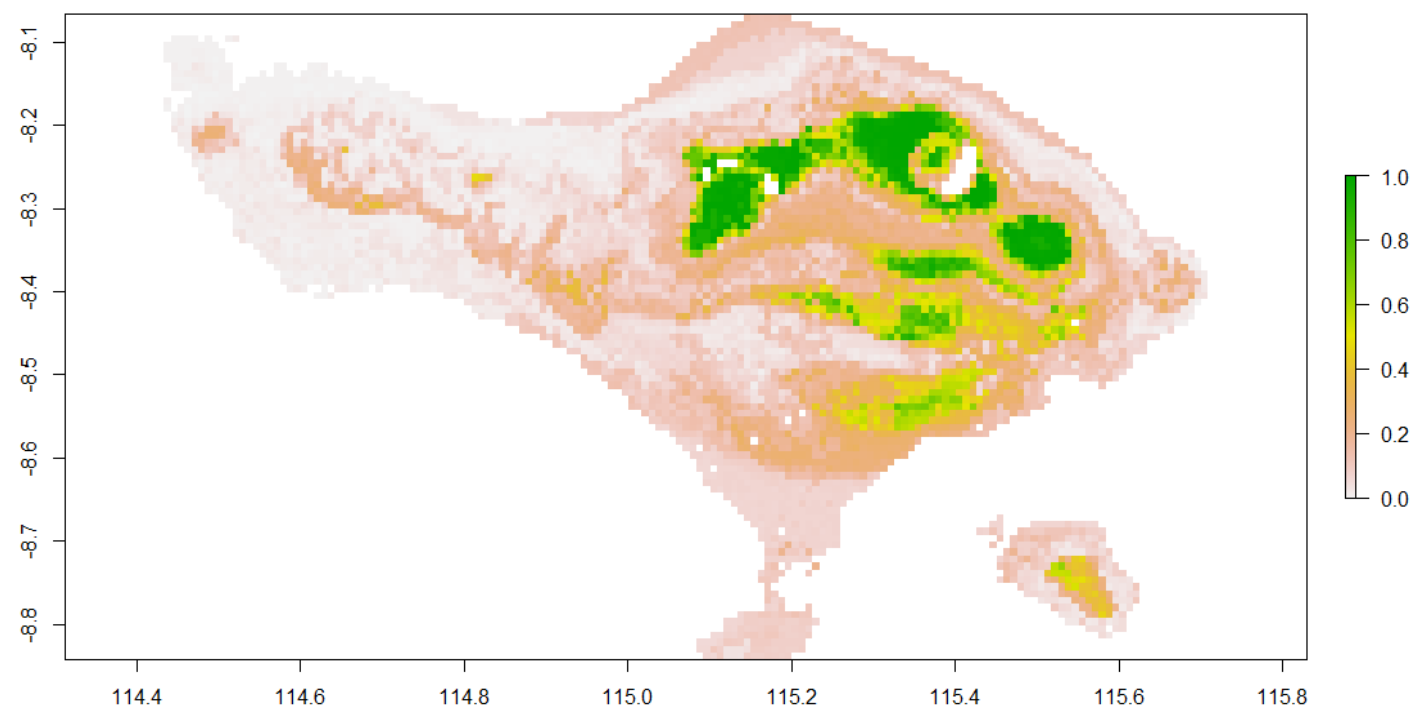

Figure 5. The predictive map of potential current distribution of Calliandra calothyrsus using Random Forest (RF)

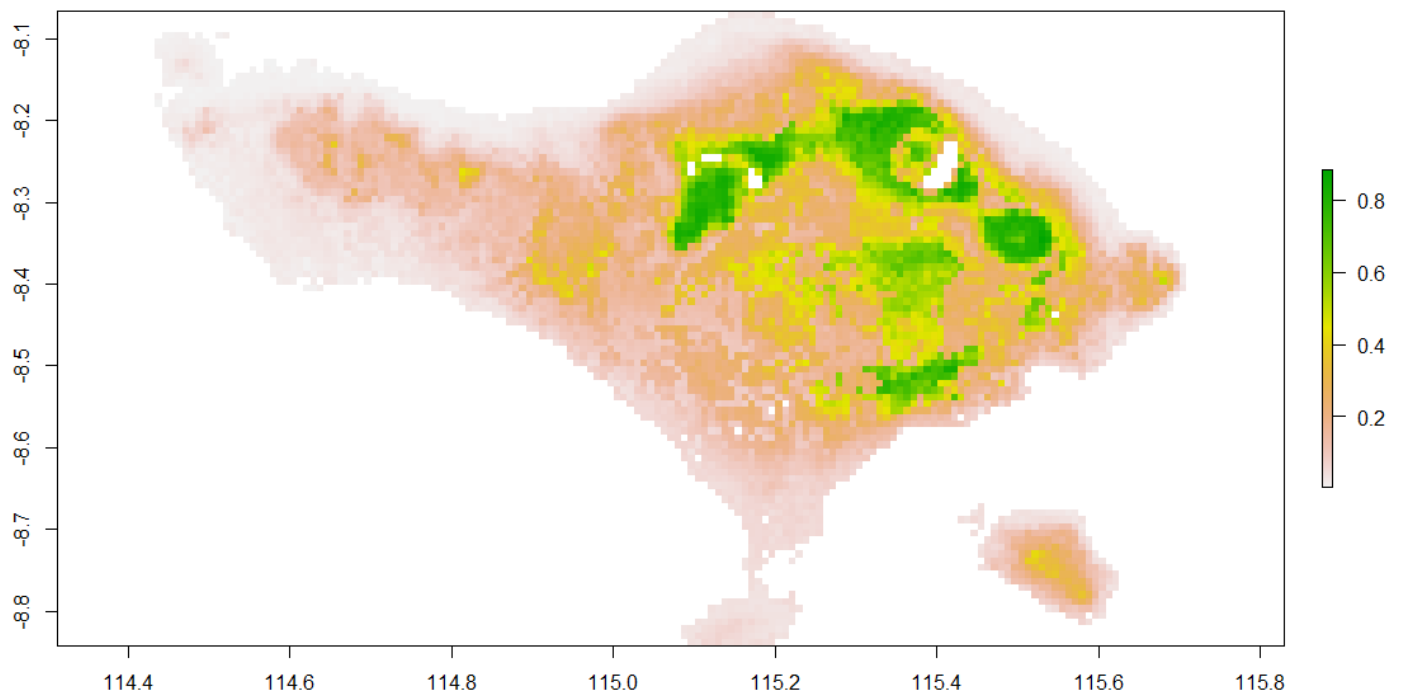

Figure 6. The predictive map of potential current distribution of Calliandra calothyrsus using MaxEnt

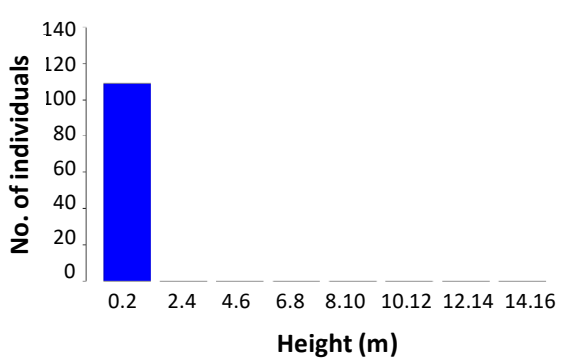

A

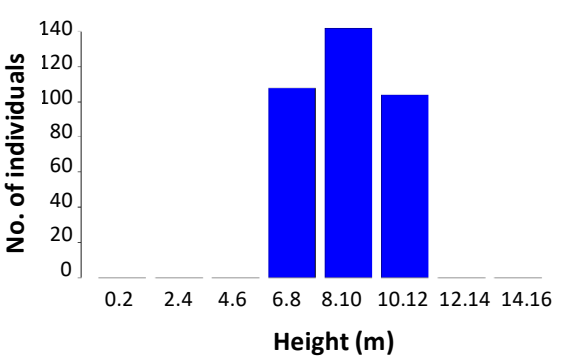

B

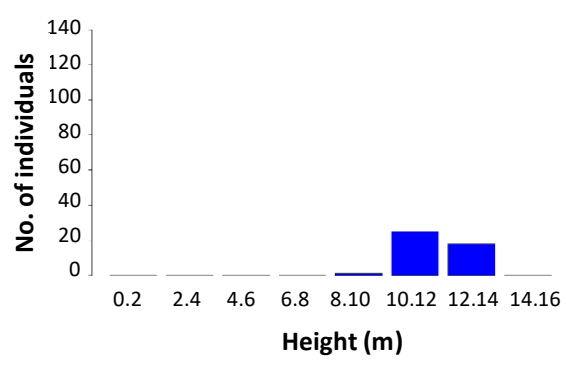

C

Figure 7. The population structure of Calliandra calothyrsus: A. Seedlings, B. Juvenile individuals, C. Mature individuals 


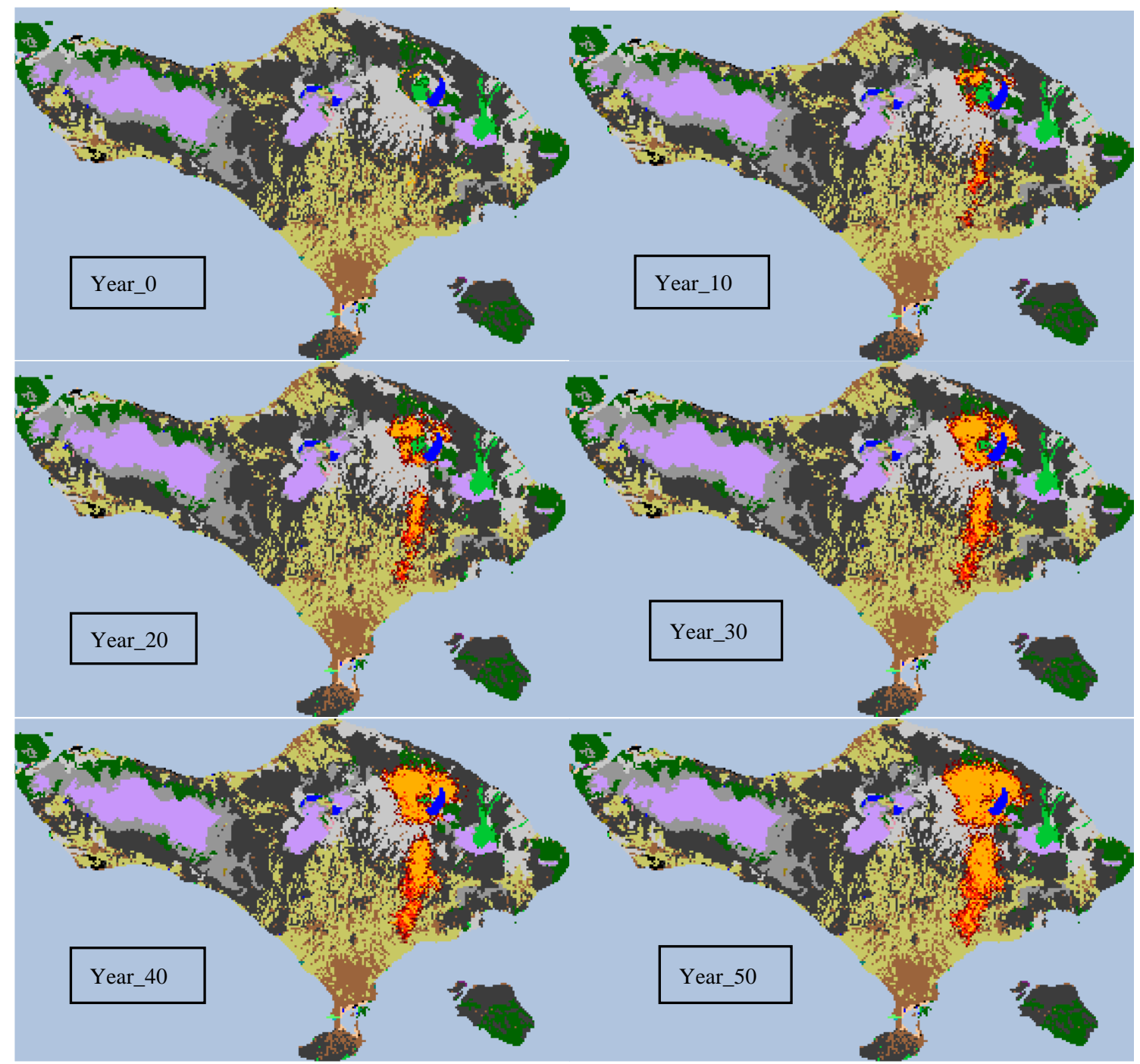

Figure 9. The population dispersal of Calliandra calothyrsus across Bali landscape. The orange color presents the growth of population of Calliandra calothyrsus throughout 50 years simulation

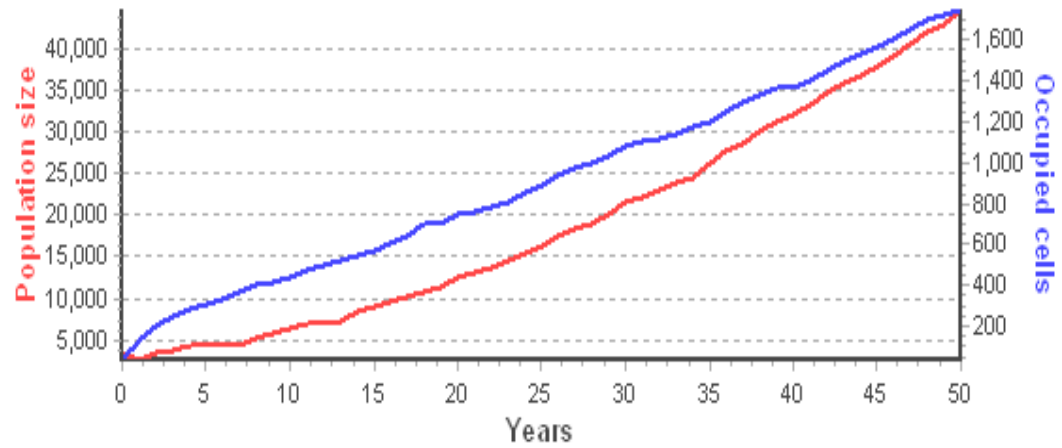

Figure 10. Population dynamic of Calliandra calothyrsus throughout 50 years of simulation

Random Forest (RF) and Maximum Entropy (MaxEnt) were chosen because those models outperform to other SDMs models. MaxEnt produced the highest AUC value, followed by SVM and RF in predicting of Zebra Wood distribution (Yudaputra et al. 2019). Both two predictive models (RF and MaxEnt) produced almost similar 
environmental variables that are the most important in terms of determining the distribution of this species. Those were elevation, precipitation, and temperature. The predictive maps will choose the regions across the landscape that have similar physical environments in which the species presence. According to the predictive map produced from RF and MaxEnt, the potential current distribution of Calliandra calothyrsus stretched from Kintamani, Bedugul, Bangli, Ubud, and small part of Gianyar and Klungkung. It mostly grew in abandoned, bare and shrublands. It seemed to well adapt in all elevation gradients from lowland to upland, but mostly in lowland. The predictive maps of potential invasion area would be useful as a consideration for management control of this species. Growing the native plants in area that predicted as a suitable habitat for $C$. calothyrsus would be the best strategies to prevent its invasiveness. When the invasive $C$. calothyrsus has been invaded and dominated in landscape, removing by cutting it down would be an alternative solution for management control.

The population structure consisted of three different classes including seedlings, juveniles, and mature individuals. According to population structure analysis (Figure 7), the juvenile individuals were the most abundant than other growth stages at all sampling plots. The juvenile individuals have height from 6 to $12 \mathrm{~m}$. At the sampling plots, the juvenile individuals of $C$. calothyrsus dominated other vegetation in their surroundings. Seedlings were relatively found in few numbers. The mature individuals were found with a height around 12-14 m which had many pods containing mature seeds. The number of mature individuals was 3-5 at each sampling plot. In the population dynamic modelling, the size of individuals is significantly increased per 10 years of simulation. This might have happened because the mature individuals were able to produce many seeds in their reproduction phase. The seeds produced by mature individuals are approximately up to 500 seeds. The number of individuals increases rapidly. Rangeshifter was a novel dynamic modelling platform used to understand the ecological and evolutionary communities (Huntley et al. 2010; Morales et al. 2010; Schurr et al. 2012; Thuiller et al. 2013). It provides a modelling of population dynamic and dispersal behaviors on landscape at different scale. The populations seem to be rapidly increased throughout 50 years of simulation because the plants will be able to produce seeds in high quantity. The dispersal pattern started from the initial occurrence and dispersed to neighboring cells. They tended to disperse in area where the condition is suitable with supporting resources available.

In conclusion, Random Forest (RF) and MaxEnt are categorized as excellent predictive models that presented with AUC value. Both two SDMs are relevant to predict the distribution pattern of Calliandra calothyrsus. The population of $C$. calothyrsus tends to have bigger number throughout 50-year simulation and disperses to the adjacent locations on landscape.

\section{REFERENCES}

Ad Hoc Panel of the Advisory Committee on Technology. 1983. Calliandra: A versatile small tree for the humid tropics. National Academy Press, Washington DC.

Allouche O, Tsoar A, Kadmon R. 2006. Assessing the accuracy of species distribution models: prevalence, kappa and the true skill statistic (TSS). J Appl Ecol 43: 1223-1232.

Breiman L. 2001. Random forests. Machine Learning 45: 5-32.

CABI. 2017. Invasive Species Compendium. CAB International.

Wallingford, UK. www.cabi.org/isc.

Caswell. 2001. Matrix Population Models: Construction, Analysis, and Interpretation. Sinauer, New York.

Cutler DR, Edwards TC, Beard KH, Cutler A, Hess KT, Gibson J, Lawler, JJ. 2007. Random forests for classification in ecology. Ecology 88: 2783-2792.

Fielding AH, Bell JF. 1997. A review of methods for the assessment of prediction errors in conservation presence/absence models. Environ Conserv 24: 38-49.

Galang MC. 1988. The effect of waterlogging on the growth of eight leguminous trees and shrub. [Thesis]. University of Queensland, Brisbane.

Graham CH. 2004. New developments in museum-based informatics and applications in biodiversity analysis. Trends Ecol Evol 19: 497-503.

Hauser S, Nyajou M, Zapfack L. 2006. Farmers' perception and use of planted Calliandra calothyrsus fallow in southern Cameroon. Conference on International Agricultural Research for Development, University of Bonn, Bonn.

Huntley B, Barnard P, Altwegg R, Chambers L, Coetzee, BWT, Gibson L. 2010. Beyond bioclimatic envelopes: dynamic species' range and abundance modelling in the context of climatic change. Ecography 33: 621-626.

Kairo M, Ali B, Cheesman O, Haysom K, Murphy S. 2003. Invasive species threats in the Carribean Region. Report to the Nature Conservancy. CAB International, Curepe, Trinidad and Tobago.

Krzanowski, WJ, Hand DJ. 2009. ROC curves for continuous data. Chapman and Hall, Boca Raton, FL.

Liaw A, Wiener, M. 2002. Classification and regression by randomForest. R News 3: 18-22.

Lobo JM, Jiménez-Valverde A, Real R. 2008. AUC: a misleading measure of the performance of predictive distribution models. Glob Ecol Biogeogr 17: 145-151.

Lowry JB, Macklin W. 1989. Calliandra calothyrsus-an Indonesian favorite goes pan-tropic. NFT Highlights 88-02. NFTA, Hawaii, USA.

Macqueen DJ. 1992. Calliandra calothyrsus: implication of plant taxonomy, ecology and biology for seed collection. Commonwealth ForRev 71: 1 .

Morales JM, Moorcroft PR, Matthiopoulos J, Frair JL, Kie JG, Powell RA, Merrill EH, Haydon DT. 2010. Building the bridge between animal movement and population dynamics. Phil Trans R Soc London B Biol Sci 365: 2289-2301.

Orwa C, Mutua A, Kindt R, Jamnadass R, Simons A. 2009. Agroforestry Database: a tree reference and selection guide version 4.0. (http://www.worldagroforestry.org/af/treedb/).

Palmer B, Macqueen DJ, Gutteridge RC. 1994.Calliandracalothyrsus-a multipurpose tree legume for humid locations. In: Gutteridge RC, Shelton HM (eds.). Forest Tree Legumes in Tropical Agriculture. CAB International, Wallingford, UK.

Phillips J, Anderson RP, Shapired RE. 2006. Maximum entropy modeling of species geographic distributions. Ecol Model 190: 231-259.

Phillips SJ, Dudik M. 2008. Modelling of species distribution with Maxent: new extensions and a comprehensive evaluation. Ecography. DOI: $10.1111 /$ j.0906-7590.2008.5203.x

Schurr FM, Pagel J, Cabral JS, Groeneveld J, Bykova O, O’Hara RB. 2012. How to understand species' niches and range dynamics: a demographic research agenda for biogeography. J Biogeogr 39: 21462162.

Stephanie. 2014. Cohen's Kappa Statistics. https://www.statisticshowto.datasciencecentral.com. [August 27, 2019].

Stephenson DB. 2000. Use of the "Odds Ratio" for diagnosing forecast skill. Weather Forecast 15: 221-232. 
Strobl C, Boulesteix AL, Zeileis A, Hothorn T. 2007. Bias in random forest variable importance measures: Illustrations, sources and a solution. BMC Bioinformatics 8: 25. DOI: 10.1186/1471-2105-8-25.

Thomas CD, Cameron A, Green R, et al. 2004. Extinction risk from climate change. Nature 427: 145-148.

Thuiller W, David R, Petr P, Midgley G, Hughes G, Rouget M. 2005. Niche-based modelling as a tool for predicting the risk of alien plant invasions at a global scale. Glob Ch Biol 11: 2234-2250.

Thuiller W, Münkemüller T, Lavergne S, Mouillot D, Mouquet N, Schiffers K, Gravel D. 2013. A road map for integrating ecoevolutionary processes into biodiversity models. Ecol Lett 16: 94-105.

United States Department of Agriculture (USDA). 2019. Invasive Plants. https://www.fs.fed.us/wildflowers/invasives/index.shtml. [August 26, 2019].

Verhoef L. 1939. Calliandra calothyrsus Meissn. Korte Mededeelingen 79. Boschbouwproefstation, Bogor, Java, Indonesia. [Dutch]

Watkinson AR. 1997. Population dynamics. In: Crawley MJ (ed.). Plant Ecology. Blackwell Scientific Publications, Oxford.
Wiersum KF, Rika IK. 1992. Calliandra calothyrsus Meissn. In: Westphal E, Jansen PCM (eds), Plant Resources of Southeast Asia: 4 Forages. PudocWageningen, Netherlands.

Yudaputra A, Astuti IP, Cropper WP. 2019. Comparing six different species distribution models with several subsets of environmental variables: Predicting the potential current distribution of Guettarda speciosa in Indonesia. Biodiversitas 20 (8): 2321-2328.

Yudaputra A, Rinandio DS, Sudarmono. 2019. Projecting the niche (suitable habitats) of invasive species: approaches, challenges, and consequences. Proceedings of The 3rd SATREPS Conference.

Yudaputra A, Robiansyah I, Rinandio DS. 2019. the implementation of artificial neural network and random forest in ecological research: species distribution modelling with presence and absence dataset. Proceedings of The 3rd SATREPS Conference.

Yudaputra A, Fijridiyanto I, Cropper WP Jr. 2020. The potential impact of climate change on the distribution pattern of Eusideroxylon zwageri (Bornean Ironwood) in Kalimantan, Indonesia. Biodiversitas 21(1): 326-333. 